\title{
Labour market institutions and amplification of employment fluctuations
}

Toyoki Matsue

To cite this article: Matsue, T. (2019). Labour market institutions and amplification of employment fluctuations. Central European Economic Journal, 6(53), 164-173. DOI: 10.2478/ceej-2019-0010.

To link to this article: https://doi.org/10.2478/ceej-2019-0010 


\title{
Central European Economic Journal
}

Toyoki Matsue $e^{1,2}$

1 International University of Kagoshima,

2 Research Fellow, Graduate School of Economics, Kobe University, corresponding author: tmatsue@bear.kobe-u.ac.jp

\section{Labour market institutions and amplification of employment fluctuations}

\begin{abstract}
Labour market reforms have been undertaken to eliminate labour market rigidities in European countries since 1970s. The important features of the reforms are the reduction in adjustment costs and the introduction of fixed-term contracts (FTC). Some empirical studies point out that employment fluctuations have become more volatile after the reforms. This paper presents a model with FTC and analyzes the effects of the key features of the reforms. Numerical examples show that an expected productivity shock causes the oscillatory behaviour of employment. Moreover, a reduction in adjustment costs amplifies fluctuations. In the labour market literature, a number of studies point out the importance of trade unions in European countries. This paper also analyzes the effects of union influence, and the numerical examples indicate that the stronger union influence leads to larger employment fluctuations.
\end{abstract}

Keywords: employment fluctuations, fixed-term contracts, trade unions, labour market reforms

JEL Codes: E24, J30, J51, J63

\section{Introduction}

Labour market institutions are one of the most influential factors in macroeconomic dynamics. As pointed out in Ghoshray, Ordóñez, and Sala (2016), high and persistent unemployment problem in the European countries has been recognised. For a persistent high unemployment rate in the European countries, labour market reforms have been undertaken to eliminate the labour market rigidities since 1970s. Faccini (2013) and Giannelli, Jaenichen, and Villosio (2012) point out that the important features of the reforms are the reduction in adjustment costs and the introduction of fixed-term contracts (FTC). Alonso-Borrego, Fernández-Villaverde, and Galdón-Sánchez (2005) and Jiménez-Rodríguez and Russo (2012) indicate that the employment fluctuations have become more volatile after the reforms. Moreover, De Serres and Murtin (2013) and OECD (2012) show that the increase in the share of FTC amplifies the employment fluctuations.

In the dynamic labour demand literature, adjustment cost models are widely used. Hamermesh and Pfann (1996) thoroughly explain the property of the adjustment cost models. In these models, indefiniteterm contracts (ITC) are assumed. Matsue (2018) creates two types of dynamic labour demand models: One is a model with FTC and the other is a model with ITC. It shows that the FTC and ITC models are different in terms of property of employment dynamics. In the ITC model, an expected productivity shock does not cause the oscillatory behaviour of total employment and new hiring, while it causes the oscillatory behaviour in the FTC model.

Layard, Nickell, and Jackman (2005) discuss the importance of trade unions in the European labour market. Union membership ratio and union coverage 
ratio are proxy variables for influence of trade union on wage setting or union power. The union membership ratio has been declining in European countries recently, whereas the union coverage ratio is still high, as shown in OECD (2015). Booth (2014) argues, using French data, that the union coverage ratio is a better measure of union influence than the union membership ratio.

A relationship between union influence and unemployment rates has been investigated extensively in the research of business cycles. Faccini and Bondibene (2012) analyses a relationship between some labour market institutions and cyclical behaviour of unemployment rates for some OECD countries. It indicates that increase in the union coverage ratio amplifies cyclical fluctuations of unemployment rates.

This paper presents a FTC model and analyzes the effects of FTC and union influence on employment dynamics. It explains some empirical evidences in the labour market. In addition to the analysis in Matsue (2018), this paper enables us to analyse the effects of supply side of labour on employment fluctuations. First, we present the model with FTC and analyzes the dynamics of the model. Similar to the dynamic labour demand model, numerical examples show that an expected productivity shock causes oscillatory behaviour of total employment and new hiring in the model with FTC. Zipperer and Skott (2011) exhibit cyclical employment trend with short-run cycles in French and Spanish economies, which is consistent with simulation results in this paper.

Second, this study analyzes the relationship between union influence and employment dynamics. The numerical examples show that the stronger union influence on wages leads to larger employment fluctuations. The strong union influence puts an upward pressure on wage rates. Then, firms need to adjust employment significantly when the productivity shock takes place. This is consistent with the results of Faccini and Bondibene (2012).

Third, this study examines the relationship between elasticity of wage with respect to employment rate and employment dynamics. The numerical examples show that the higher elasticity of wage with respect to the employment rate leads to smaller employment fluctuations. The firms do not need to adjust employment largely because wage varies significantly when the elasticity of wage with respect to the employment rate is high.

The rest of this paper is organised as follows: Section 2 sets up the model, Section 3 discusses the property of the model with simulation analysis, Section 4 investigates the influence of the labour supply side on employment fluctuations, and Section 5 concludes the paper.

\section{Model}

Let us set up the model with FTC. Firms plan their production during the finite time period $T$, and they produce homogeneous goods. The objective function is as follows:

$$
\max _{h_{t}, K_{t}} \sum_{t=0}^{T} \beta^{t}\left[\left(A_{t} L_{t}\right)^{\alpha} K_{t}^{1-\alpha}-w_{t} L_{t}-\left(r_{t}+\delta\right) K_{t}-(\tau / 2) h_{t}^{2}\right],
$$

where $0<\beta<1$ is discount factor, $A_{t}$ is positive productivity parameter, $L_{t}$ is total employment, $h_{t}$ is new hiring, and $K_{t}$ is capital. Moreover, $w_{t}$ is wage rate, $r_{t}$ is real interest rate, $\delta$ is depreciation rate, and $(\tau / 2) h_{t}^{2}$ is labour adjustment cost function, where $\tau \geq 0$. This type of adjustment cost function is also used in Cabo and Martín-Román (2019), Vogel (2017), and Gali and van Rens (2010). Suppose that a firm makes an agreement for an FTC with labour, in which the term of contracts is two periods. The total employment is as follows:

$L_{t}=h_{t}+h_{t-1}$

Then, $h_{-1}, h_{0}, h_{T}, h_{T+1}$, and $K_{0}$ are given. The firm decides $h_{t}$ from period 1 to $T-1$ and $K_{t}$ from period 1 to $T$. The first-order conditions are as follows:

$$
\begin{aligned}
& \sum_{s=t}^{t+1} \beta^{s} \alpha A_{s} l_{s}^{\alpha-1}=\sum_{s=t}^{t+1} \beta^{s} w_{s}+\beta^{t} \tau h_{t}, t=1,2, \ldots, T-1 \\
& (1-\alpha) l_{t}^{\alpha}=r_{t}+\delta, t=1,2, \ldots, T
\end{aligned}
$$

where $l_{t} \equiv A_{t} L_{t} / K_{t}$.

Similar to Blanchard (1997), suppose that the aggregate supply function is as follows:

$w_{t}=\theta\left(\frac{L_{t}}{N}\right)^{\gamma}$ 
where $N$ denotes labour force in this economy that is assumed to be constant, $\theta$ is wage at zero unemployment, and $\gamma \geq 1$ is wage elasticity with respect to the employment rate $L_{t} / N$. In the aggregate supply function, it is assumed that the wage is an increasing function of the employment rate. Adachi and Nakamura (2015) point out that this relationship is justified by either wage bargaining theory or efficiency wage theory. The wage bargaining theory and efficiency wage theory are thoroughly discussed in Layard et al. (2005). The increase in $\theta$ exerts an upward pressure on the wage rate. Blanchflower and Bryson (2002) and Nickell (1997) point out that the union puts an upward pressure on the wage rate. Although there are many ways to interpret the increase in $\theta$, we interpret it as union influence on wage in this study. Eq. (5) is transformed as follows:

$w_{t}=\theta\left(\frac{l_{t}}{n_{t}}\right)^{\gamma}$

where $n_{t} \equiv A_{t} N / K_{t}$. From Eqs (3) and (6), we obtain the following equation:

$$
\sum_{s=t}^{t+1} \beta^{s} \alpha A_{s} l_{s}^{\alpha-1}=\sum_{s=t}^{t+1} \beta^{s} \theta\left(\frac{l_{s}}{n_{s}}\right)^{\gamma}+\beta^{t} \tau h_{t} .
$$

Eq. (7) is rewritten as follows:

$$
\frac{l_{t}}{n_{t}}=\left[\frac{\alpha A_{t} l_{t}^{\alpha-1}+\alpha \beta A_{t+1} l_{t+1}^{\alpha-1}-\beta \theta\left(l_{t+1} / n_{t+1}\right)^{\gamma}-\tau h_{t}}{\theta}\right]^{\frac{1}{\gamma}} \text {, }
$$

which is the employment rate. Then, the unemployment rate is as follows:

$\frac{N-L_{t}}{N}=1-\frac{l_{t}}{n_{t}}$.

(9) $K=\left(\frac{s}{\delta}\right)^{\frac{1}{\alpha}} A L$.

Suppose that agents save and invest a fixed fraction $S$ of production $Y_{t}$.

$$
I_{t}=s Y_{t}, 0<s<1
$$

It is assumed that equation for capital dynamics with depreciation rate $\delta$ is as follows:

$$
K_{t+1}=I_{t}+(1-\delta) K_{t}
$$

From Eqs (10) and (11) and the production function, the capital dynamics is as follows:

$$
K_{t+1}=s l_{t}^{\alpha} K_{t}+(1-\delta) K_{t} .
$$

The equilibrium is determined by Eqs (2), (7), and (12); the initial conditions; and the terminal conditions. Now, consider the steady state $h_{t+1}=h_{t}=h, L_{t+1}=L_{t}=L$, $K_{t+1}=K_{t}=K$, and $A_{t+1}=A_{t}=A$, that is $l_{t+1}=l_{t}=l$. Then, Eqs (2), (7), and (12) are transformed as follows:

$h=\frac{1}{2} L$,

$l=\left[\frac{(1+\beta) \theta(L / N)^{\gamma}+\tau h}{(1+\beta) \alpha A}\right]^{\frac{-1}{1-\alpha}}$,

$l=\left(\frac{\delta}{s}\right)^{\frac{1}{\alpha}}$.

Eq. (13) indicates that the new hiring is as much as the labour who leaves a job in the steady state. From Eq. (11), we find that the investment is equal to the depreciation at the steady state. In addition, the investment is determined as a fixed fraction $s$ of production. Hence, $l$ is determined by the saving rate and depreciation rate as shown in Eq. (15). From Eqs (13)-(15), we obtain the steady state values $h^{*}, L^{*}$, and $l^{*}$. Moreover, using $l=A L / K$, Eq. (15) is transformed as follows:

If we substitute $L^{*}$ in Eq. (16), then we obtain the steady state value $K^{*}$. 


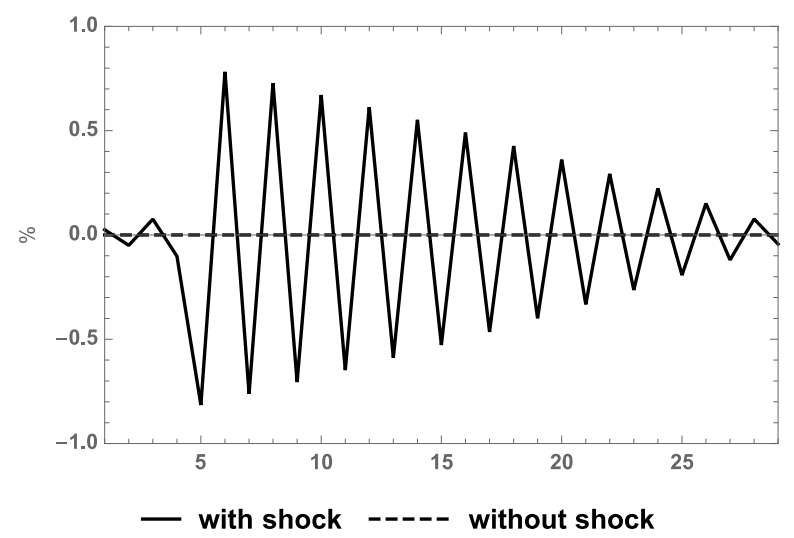

(a)

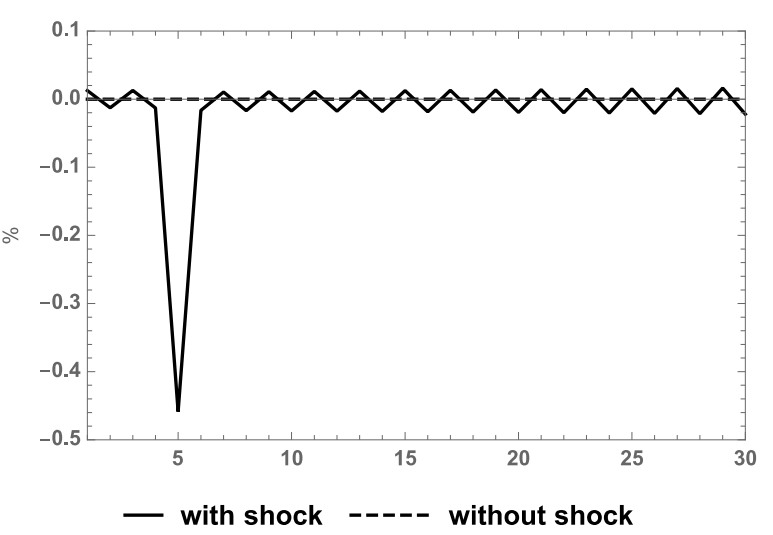

(b)

Fig. 1: Employment fluctuations with $\tau=0$ : (a) New hiring and (b) Total employment.

\section{Model Properties}

Now, we analyse the effects of expected productivity shocks on employment by running some simulations. We set the parameter values as given in Table 1 . The parameters $\alpha, \beta$, and $\delta$ are the same values used in Jaimovich and Revelo (2008). We set the parameters $\gamma$ and $\theta$ that are in the wage setting equation to the same values used in Blanchard (1997). The parameter $\tau$ is the same value used in Cabo and Martín-Román (2019). The value of parameter $S$ is the same as used in Novales, Fernández, and Ruiz (2010, Chapter 2). Suppose that the shock takes place at period 5 and then it returns at period 6 , and $T=30$. Here, negative shock to productivity is expected, which decreases $1 \%$ of the productivity. In the beginning of planning period, the economy is at the steady state. Then, it is assumed that the total employment is $100\left(h_{0}=h_{-1}=50\right.$, i.e., $\left.L_{0}=100\right)$. The initial productivity level is chosen by having $L_{0}=100$. The initial capital $K_{0}$ is chosen by substituting $A_{0}$ and $L_{0}=100$ in Eq. (16). The terminal condition is $h_{31}=h_{30}=50$.

Figures 1 and 2 show the simulation results. These figures show the deviation of new hiring or total employment when the negative shock takes place from their steady state values. If the negative shock takes place at period 5 , the firm decreases new hiring at periods 4 and $5\left(h_{4}\right.$ and $\left.h_{5}\right)$ to adjust the total employment at period $5\left(L_{5}\right)$. Then, the firm faces less employment than the optimum employment at period 4 $\left(L_{4}\right)$ and period $6\left(L_{6}\right)$. Therefore, it increases $h_{3}$ and $h_{6}$
Tab. 1: Parameters in Section 3.

\begin{tabular}{lll}
\hline$\alpha$ & Parameter in production function & 0.64 \\
\hline$\beta$ & Discount factor & 0.985 \\
\hline$\gamma$ & $\begin{array}{l}\text { Elasticity of wage with respect to employment } \\
\text { rate }\end{array}$ & 1.0 \\
\hline$\delta$ & Depreciation rate & 0.0125 \\
\hline$\theta$ & Wage at zero unemployment & 0.35 \\
\hline$\tau$ & Adjustment cost & 0.0 or 0.1 \\
\hline$\sigma$ & Turnover rate & 0.5 \\
\hline$s$ & Saving rate & 0.30 \\
\hline$N$ & Labour force & 110.0 \\
\hline
\end{tabular}

to avoid falling into the condition because $L_{4}=h_{4}+h_{3}$ and $L_{6}=h_{6}+h_{5}$. These decisions cause increase in the total employment at periods 3 and 7 . Hence, the firm decreases new hiring at periods 2 and 7 . These decisions are repeated throughout the planning period. With the adjustment cost case, the behaviour is smaller than the no adjustment cost case. This is because of the adjustment costs play a role in smoothing the labour adjustments. Similar to dynamic labour demand models with FTC analysed by Matsue (2018), the model shows oscillatory behaviour of employment even if the firm does not incur the adjustment costs.

To understand the role of FTC, the FTC model should be compared with a model without FTC. It is assumed that employees leave their job by a fixed 


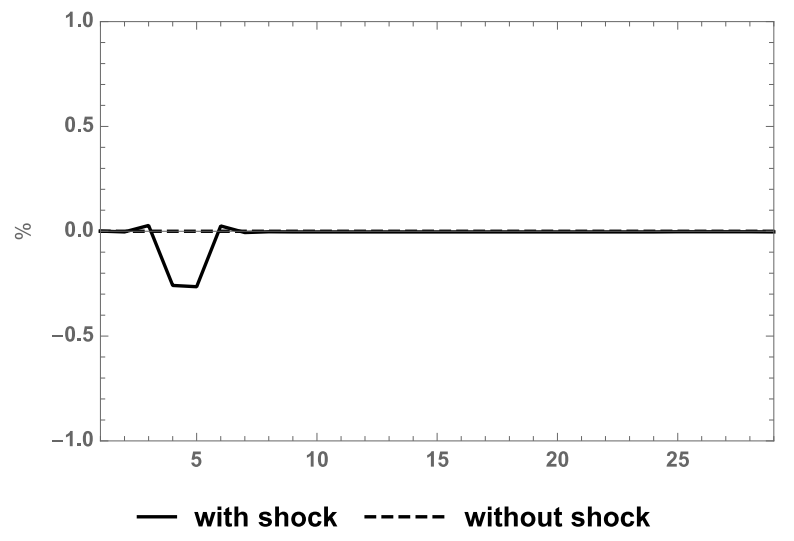

(a)

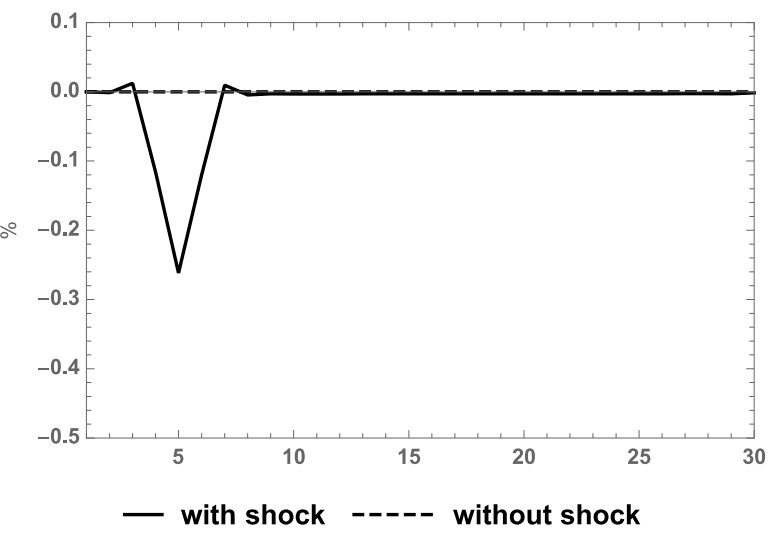

(b)

Fig. 2: Employment fluctuations with $\tau=0.1$ : (a) New hiring and (b) Total employment.

fraction $0<\sigma<1$ of total employment. The employment dynamics is as follows:

$L_{t}=(1-\sigma) L_{t-1}+h_{t}$

where $\sigma$ is turnover rate. This type of employment dynamics is frequently assumed in the dynamic labour demand literature. The firm optimises objective function (1), subject to the constraint of Eq. (17). Suppose that $\tau=0$ in objective function (1), then the first-order conditions are as follows:

$\alpha A_{t} l_{t}^{\alpha-1}=w_{t}$,

$(1-\alpha) l_{t}^{\alpha}=r_{t}+\delta$

Similar to the FTC model, consider the employment rate. From Eqs (6) and (18), we obtain the following equation:

$\alpha A_{t} l_{t}^{\alpha-1}=\theta\left(\frac{l_{t}}{n_{t}}\right)^{\gamma}$.

If we transform Eq. (20), then the employment rate is obtained as follows:

$$
\frac{l_{t}}{n_{t}}=\left[\frac{\alpha A_{t} l_{t}^{\alpha-1}}{\theta}\right]^{\frac{1}{\gamma}} .
$$

Unemployment rate is obtained by substituting Eq. (21) in Eq. (9). The household behaviour is the same with the FTC model. Hence, the equilibrium is determined by Eqs (12), (17), and (20). At the steady state, Eqs (12), (17), and (20) are as follows:

$h=\sigma L$,

$l=\left[\frac{\theta(L / N)^{\gamma}}{\alpha A}\right]^{\frac{-1}{1-\alpha}}$,

$l=\left(\frac{\delta}{s}\right)^{\frac{1}{\alpha}}$

Equation (22) shows that the new hiring is as much as the labour who leaves a job in the steady state. From Eqs (22)-(24), we obtain the steady state values $h^{*}, L^{*}$, and $l^{*}$ . From $l=A L / K$, Eq. (24) is rewritten as follows:

$K=\left(\frac{s}{\delta}\right)^{\frac{1}{\alpha}} A L$.

Then, by substituting $L^{*}$ in Eq. (25), we obtain the steady state value $K^{*}$. Compare Eqs (13)-(15) with Eqs (22)(24); if $\tau=0$ and $\sigma=1 / 2$, then the steady state values between the two models are the same. 


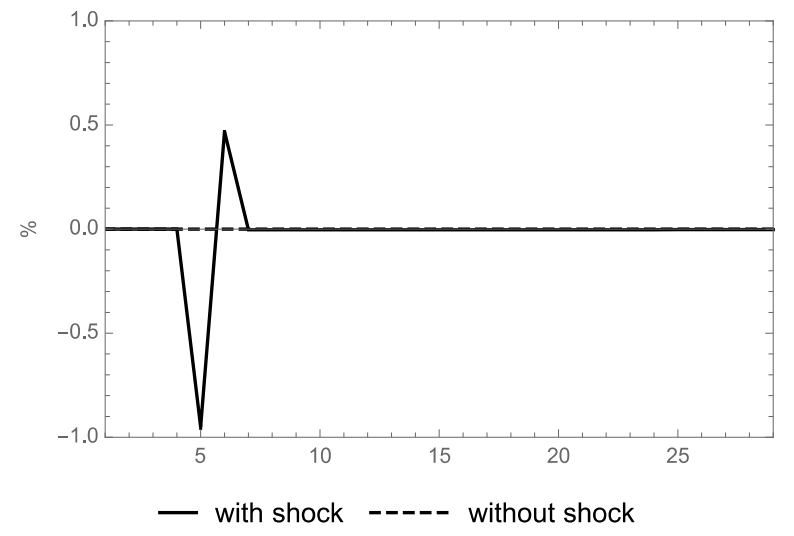

(a)

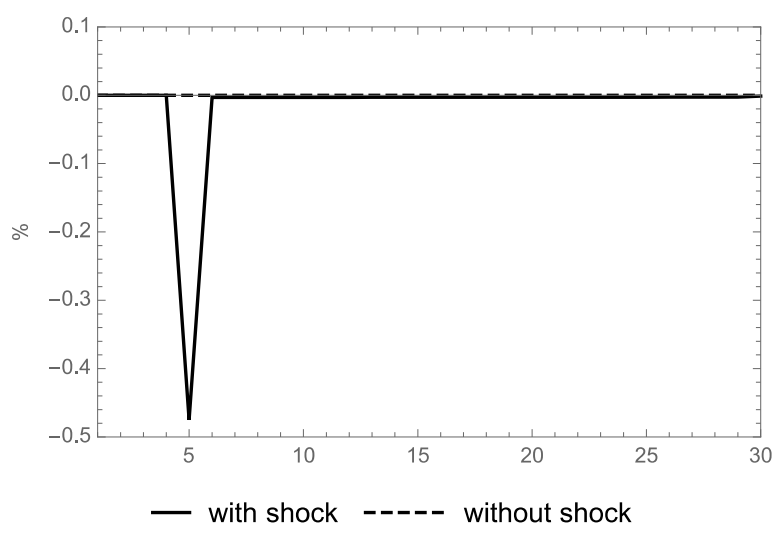

(b)

Fig. 3: Employment fluctuations without fixed-term contracts: (a) New hiring and (b) Total employment.

The simulation results are shown in Figure 3. The figure shows the deviation of new hiring or total employment when the negative shock takes place from their steady state values. The assumptions about the shock are similar to the case with the FTC model. To compare with the FTC model, at the steady state, half of the total employment leaves the job at the end of the period $(\sigma=0.5)$. The other parameters are the same in Table 1. If the negative shock takes place at period 5 , then the firm decreases new hiring to adjust the total employment at period 5. The model without FTC does not show the oscillatory behaviour if an expected productivity shock takes place.

Proposition 1. Suppose that an expected temporary productivity shock takes place. Then, it causes the oscillatory behaviour of total employment and new hiring even if the firm does not incur any adjustment costs in the model with FTC.

\section{Labour Supply and Employment Fluctuations}

In this section, we run some simulations to analyse the effects of labour supply side on employment dynamics, i.e., a relationship between union influence on wage $\theta$ and employment dynamics, and a relationship between elasticity of wage with respect to employment rate $\gamma$ and employment dynamics. These parameters are included in the wage setting function.

\subsection{Relationship between union influence and employment dynamics}

We analyse a relationship between union influence on wage $\theta$ and employment dynamics. We set the parameter values as given in Table 2. Suppose that an expected negative shock to productivity takes place at period 5 , which decreases $1 \%$ of the productivity at period 5. The shock is temporary, i.e., the level of productivity decreases at period 5 and then it returns at period 6 . In the beginning of the planning period, the economy is at the steady state. The assumption of the simulations is the same as in the previous section, except for the assumption about the union influence on wage.

Figure 4 shows the simulation results of the model. The figure shows the deviation of total employment when the negative shock takes place from the steady state value. Figure 3 shows that the stronger union influence leads to larger employment fluctuations. The deviation of total employment when the negative shock takes place from the steady state value at period 5 is as follows: $-0.261674 \%$ if $\theta=0.35,-0.272612 \%$ if $\theta=1.0$, $-0.279727 \%$ if $\theta=1.5$, and $-0.28598 \%$ if $\theta=2.0$. The increase in $\theta$ puts upward pressure on the wage rate. Hence, the firm adjusts employment significantly when the productivity shock takes place.

In this model, we assume $N=L_{t}+U_{t}$ and the unemployment rate is defined as Eq. (9), where $N$ is constant. Thus, the stronger union influence leads to the larger oscillatory behaviour of the unemployment rate. 


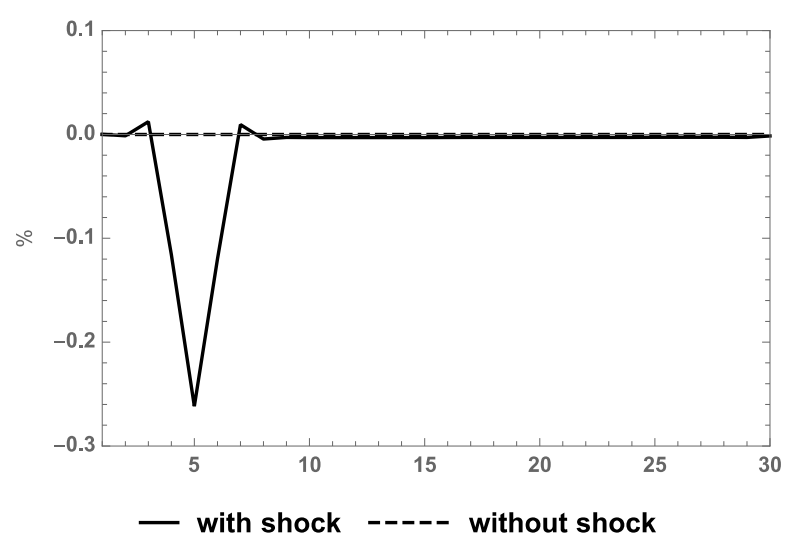

(a)

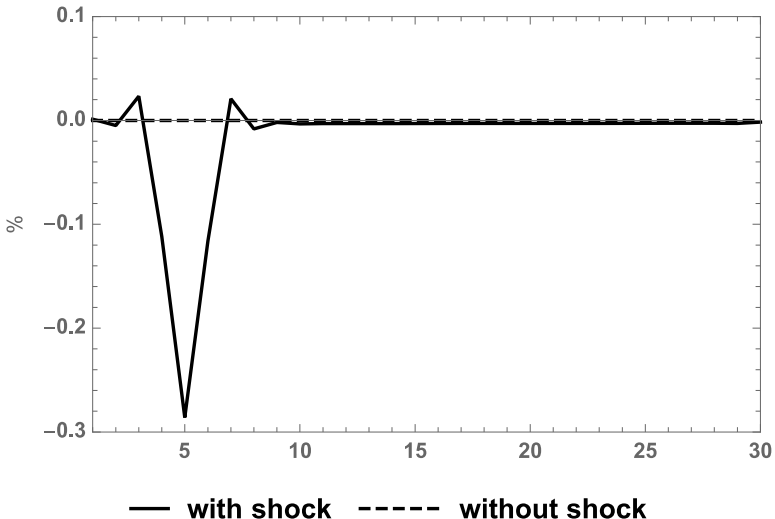

(b)

Figure 4. Union influence and employment fluctuations: (a) $\theta=0.35$ and (b) $\theta=2.0$.

Tab. 2: Parameters in Section 4.1

\begin{tabular}{lll}
\hline$\alpha$ & Parameter in production function & 0.64 \\
\hline$\beta$ & Discount factor & 0.985 \\
\hline$\gamma$ & $\begin{array}{l}\text { Elasticity of wage with respect to } \\
\text { employment rate }\end{array}$ & 1.0 \\
\hline$\delta$ & Depreciation rate & 0.0125 \\
\hline$\theta$ & Wage at zero unemployment & $0.35,1.0,1.5$, or 2.0 \\
\hline$\tau$ & Adjustment cost & 0.1 \\
\hline$s$ & Saving rate & 0.30 \\
\hline$N$ & Labour force & 110.0 \\
\hline
\end{tabular}

This result is consistent with the empirical results of Faccini and Bondibene (2012).

Proposition 2. Suppose that an expected temporary productivity shock takes place. Then, the stronger the union influence on wage leads to larger employment fluctuations.

\subsection{Relationship between elasticity of wage with respect to employment rate and employment dynamics}

We analyse a relationship between elasticity of wage with respect to the employment rate $\gamma$ and employment dynamics. We set the parameter values as given in Table 3. The assumption of the simulations is the same as in the previous section, except for the assumption about the elasticity of wage with respect to the employment rate $\gamma$. Figure 5 shows the simulation results. The figure
Tab. 3: Parameters in Section 4.2.

\begin{tabular}{lll}
\hline$\alpha$ & Parameter in production function & 0.64 \\
\hline$\beta$ & Discount factor & 0.985 \\
\hline$\gamma$ & $\begin{array}{l}\text { Elasticity of wage with respect to } \\
\text { employment rate }\end{array}$ & $1.0,2.0,3.0$, or 4.0 \\
\hline$\delta$ & Depreciation rate & 0.0125 \\
\hline$\theta$ & Wage at zero unemployment & 0.35 \\
\hline$\tau$ & Adjustment cost & 0.1 \\
\hline$s$ & Saving rate & 0.30 \\
\hline$N$ & Labour force & 110.0 \\
\hline
\end{tabular}

shows the deviation of total employment when the negative shock takes place from the steady state value.

It shows that the increase in $\gamma$ causes the decrease in employment fluctuations. The deviation of total employment when the negative shock takes place from the steady state value at period 5 is as follows: $-0.261674 \%$ if $\gamma=1.0,-0.246641 \%$ if $\gamma=2.0,-0.235388 \%$ if $\gamma=3.0$, and $-0.22686 \%$ if $\gamma=4.0$. Suppose that the elasticity of wage with respect to the employment rate is high. Then, the firm does not need to adjust employment largely because the wage varies significantly when the shock takes place.

Proposition 3. Suppose that an expected temporary productivity shock takes place. Then, the higher elasticity of wage with respect to the employment rate leads to smaller employment fluctuations. 


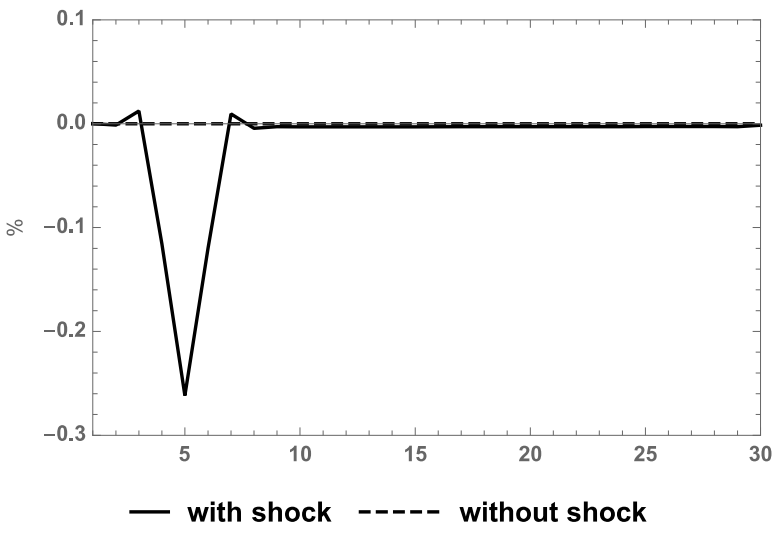

(a)

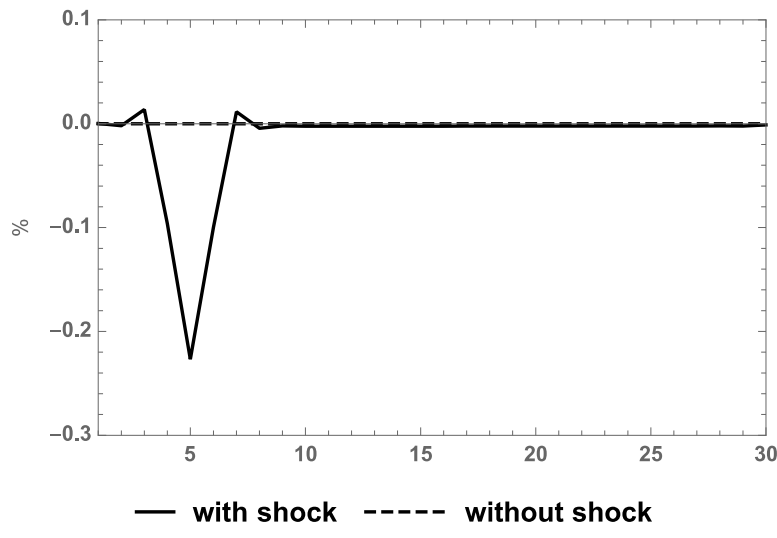

(b)

Fig. 5: Elasticity of wage with respect to employment rate and employment fluctuations: (a) $\gamma=1.0$ and (b) $\gamma=4.0$.

\section{Concluding Remarks}

Unemployment and employment dynamics have been studied in many theoretical and empirical analyses. The labour market institutions are one of the most influential factors in macroeconomic dynamics. This study analyzes the impact of labour market institutions on employment fluctuations using a model with FTC. Numerical examples show that the total employment and new hiring behave cyclically if an expected shock takes place. Moreover, the reduction in adjustment cost amplifies the fluctuations in the model.

The union influence in the labour market is important because the union coverage ratio is still at a high level. This study also analyzes the relationship between the union influence and employment dynamics. The numerical examples show that the stronger union influences on wage lead to larger employment fluctuations. The strong union influence puts upward pressure on the wage rate. Then, the firm needs to adjust its employment significantly when the productivity shock takes place, which is consistent with the results of Faccini and Bondibene (2012).

Further, this study analyzes additional influence of the labour supply side on employment fluctuations. The numerical examples show that the higher elasticity of wage with respect to the employment rate leads to smaller employment fluctuations. The firm does not need to adjust its employment largely because the wage varies significantly when the elasticity of wage with respect to the employment rate is high.

Nevertheless, the model in this study is restricted to a simple case in which the term of contracts is only two periods. Hence, it is necessary to analyse a more general case. Moreover, the models could be extended to consider the endogenous labour supply and intertemporal optimisation of consumption. Further investigation of these issues remains to be undertaken.

\section{Acknowledgement}

The author wishes to thank Tamotsu Nakamura, Mototsugu Fukushige, Ryosuke Nakamura and participants at the KMSG conference for their valuable comments.

\section{References}

[1] Adachi, H., \& Nakamura, T. (2015). Growth and fluctuations in demand-constrained economies: A medium-run macroeconomic analysis. In $\mathrm{H}$. Adachi, T. Nakamura, \& Y. Osumi (Eds.), Studies in medium-run macroeconomics: Growth, fluctuations, unemployment, inequality and policies (pp. 3-35). Singapore: World Scientific Publishing Co. Pte. Ltd.

[2] Alonso-Borrego, C., Fernández-Villaverde, J., \& Galdón-Sánchez, J. E. (2005). Evaluating labor 
market reforms: A general equilibrium approach. NBER Working Paper, 11519.

[3] Blanchard, O. J. (1997). The medium run. Brookings Papers on Economic Activity, 2, 89-158.

[4] Blanchflower, D. G., \& Bryson, A. (2002). Changes over time in union relative wage effects in the UK and the US revisited. NBER Working Paper, 9395.

[5] Booth, A. L. (2014). Wage determination and imperfect competition. Labour Economics, 30, 53-58.

[6] Cabo, F., \& Martín-Román, A. (2019). Dynamic collective bargaining and labor adjustment costs. Journal of Economics, 126, 103-133.

[7] De Serres, A., \& Murtin, F. (2013). Do policies that reduce unemployment raise its volatility? OECD Economics Department Working Paper, 1020.

[8] Faccini, R. (2013). Reassessing labour market reforms: Temporary contracts as a screening device. Economic Journal, 124, 167-200.

[9] Faccini, R., \& Bondibene, C. R. (2012). Labour market institutions and unemployment volatility: Evidence from OECD countries. Bank of England Working Paper, 461.

[10] Gali, J., \& van Rens, T. (2010). The vanishing procyclicality of labor productivity. IZA Discussion Paper, 5099.

[11] Ghoshray, A., Ordóñez, J., \& Sala, H. (2016). Euro, crisis and unemployment: Youth patterns, youth policies? Economic Modeling, 58, 442-453.

[12] Giannelli, G. C., Jaenichen, U., \& Villosio, C. (2012). Have labor market reforms at the turn of the millennium changed the job and employment durations of new entrants? A comparative study for Germany and Italy. Journal of Labor Research, 33, 143-172.

[13] Hamermesh, D. S., \& Pfann, G. A. (1996). Adjustment costs in factor demand. Journal of Economic Literature, 34, 1264-1292.

[14] Jaimovich, N., \& Revelo, S. (2008). News and business cycles in open economies. Journal of Money, Credit and Banking, 40(8), 1699-1711.

[15] Jiménez-Rodríguez, R. \& Russo, G. (2012). Aggregate employment dynamics and (partial) labour market reforms. Bulletin of Economic Research, 64(3), 430-448.

[16] Layard, R., Nickell, S., \& Jackman, R. (2005). Unemployment: Macroeconomic performance and the labour market. New York, NY: Oxford University Press Inc.

[17] Matsue, T. (2018). Fixed-term contracts as a source of labour demand fluctuations. Applied Economics Letters, 25(9), 611-614.

[18] Nickell, S. (1997). Unemployment and labor market rigidities: Europe versus North America. Journal of Economic Perspectives, 11(3), 55-74.

[19] Novales, A., Fernández, E., \& Ruiz, J. (2010). Economic growth: Theory and numerical solution methods. Berlin, Heidelberg, Germany: Springer.

[20] OECD. (2015). Economic policy reforms 2015: Going for growth. Paris, France: OECD Publishing.

[21] OECD. (2012). OECD employment outlook. Paris, France: OECD Publishing.

[22] Vogel, L. (2017). Structural reforms at the zero bound. European Journal of Political Economy, 48, 74-90.

[23] Zipperer, B., \& Skott, P. (2011). Cyclical patterns of employment, utilization, and profitability. Journal of Post Keynesian Economics, 34(1), 25-58. 